\title{
The Meltdown Years: The Unfolding of the Global Economic Crisis
}

Book Review

\author{
Author: Wolfgang Münchau \\ Reviewed by: Shiva Kumar Srinivasan \\ Behavioral Sciences, IIPM Chennai, India \\ sksrinivasan2008@hotmail.com
}

Münchau sets out to answer a simple set of questions: Why did the economic crisis happen? What were its preconditions? What must we do now to repair the situation? While the answers to the first two questions have been attempted before, this is one of the most lucid books to answer the third question. Münchau divides the book itself into three long chapters which take the reader up to the economic crisis, the crisis itself, and the policy recommendations that will hopefully prevent it from happening again. The arguments are aimed at the intelligent layperson who wants to understand how economic forces impact society during a meltdown. The book is accompanied not only by a glossary of technical terms in finance but also has an interesting appendix on asset bubbles. The section on bubbles is inspired by John Kenneth Galbraith's book on financial euphoria, which enjoyed a revival in sales during the recent crisis. The author has also included a number of 'sidebars' that define and describe important economic developments, regulatory frameworks, technical terms and theories in the areas of macroeconomics and finance that the reader may not necessarily be familiar with, but an understanding of which is a prerequisite for making sense of this book and its policy recommendations. This book will also be of interest to students of macroeconomics, finance, law, general management, and regulation. It has interesting discussions on what exactly should constitute the explanatory criteria while generating policy options and making decisions in the domain of the macro-economy. The main achievement of this book is that it will appeal to readers with varying levels of knowledge in macroeconomics and finance given its formatting strategy. Even readers who have been through copious news-reports in the media will gain theoretical insights from the retroactive structuring of the crisis in this book.

What was the situation before the financial meltdown? Münchau starts by explaining what a bank is, how banks operate, the differences between regular banking and investment banking, the significance of the GlassSteagall Act of 1933, the setting up of the Federal Deposit Insurance Corporation (FDIC), the subsequent repeal of the 1933 provisions under the aegis of the Gramm, Leach, Bliley Bill of 1999, the role of the Basle conventions in determining capital adequacy ratios in banking, the exponential rise of innovations in the financial sector through the use of securitization, the invocation of mathematical models of risk management, the inadequate regulation of the mortgage markets, the failure of credit rating agencies in the lead up to the crisis in 2008, and so on. Each of these ideas warrants a simple expository essay which will help to supplement whatever the reader needs to brush up on in order to understand the main arguments and policy recommendations in the book. These essays are not completely woven into the main narrative, but serve to punctuate the crisis narrative at strategic intervals. The essays are written in a style that makes it possible to read them both within the trajectory of the main argument and, if necessary, as separate pieces. It also includes brief cases of both the banks and insurance firms that collapsed during the crisis and those that were bailed out in 2008. While there is now a growing literature on the economic crisis featuring separate accounts of each of these institutions, the focus here is not on any particular bank that went under but on the process of the actual meltdown as a macroeconomic phenomenon. There are also interesting debates on the pros and cons of deregulation in the financial sector and the role that was played by specific pieces of legislation in triggering the crisis.

The second section of the book, which focuses on the meltdown, starts by explaining the role of central banks, their role as lenders of last resort, the different tools available with central banks to manage a crisis, the theoretical and policy differences between the U.S. Federal Reserve and other central banks including the Bank for International Settlements (BIS), and the role that they played in stabilizing the banking sector by infusing liquidity through a varied set of monetary policy mechanisms. Münchau also describes the policy mechanisms invoked by central bankers to regulate the money supply and the role played by the interbank 
markets such as LIBOR and EURIBOR in this process. Some of the more interesting parts of the book include descriptions of the meltdown in Iceland where the government had difficulty in bailing out the banks given that the losses accrued by Icelandic banks were many times Iceland's GDP. This was a peculiar problem in the smaller countries where banks were much larger than the countries in which they operated. The problem for central banks was not just on how to rescue particular banks but also on how to rescue the banking system as such. It is therefore important for the reader to understand the range of monetary policy tools and the modalities of intervention that central banks like the U.S. Federal Reserve are able to deploy during a crisis to appreciate the magnitude of the problems that they have to solve. In order to do so, Münchau explains the typical balance sheet of the Fed in terms of what items are defined as 'assets' and what items are defined as 'liabilities'.

The main assets include 'credits to financial institutions' and 'securities held' while the main liabilities comprise the 'currency in circulation' and 'bank reserves'. The formula that helps differentiate between these categories is 'not to use a common-sense definition of assets and liabilities, but define assets as claims the central banks have on others, and liabilities as claims others have on the central bank'. For understanding the difference between what the Fed defines as assets or liabilities, it is important to differentiate between different forms of monetary policy interventions such as open-market operations and quantitative easing. This is especially the case in situations when the interest rate is already zero and the Fed 'cannot provide further stimulus by means of cutting interest rates further': the only remaining option in such situations is to 'print money'. The former, including credit easing, fall under the assets side of the balance sheet whereas quantitative easing pertains to the liabilities section of the balance sheet. Situating a monetary policy intervention in terms of the spatial differentiation of the balance sheet provides the reader with a more nuanced understanding of the strategic implications of a monetary policy intervention rather than work merely with a list of monetary policy tools. Recent interventions by the U.S. Fed and leading central banks have seen an appreciation of the amounts in their balance sheets from a modest $\$ 700$ billion to over $\$ 2$ trillion. Münchau also discusses the political pros and cons of the Troubled Asset Relief Program (TARP) that was initiated by U.S. Secretary of the Treasury Hank Paulson before moving on to policy recommendations that will hopefully prevent such crises in the future.

In the third and last chapter, Münchau thinks through the usual list of suspects to determine the causal factors behind the crisis. A number of economists have already drawn up their respective lists of what they consider to be the relevant factors. A long list of factors will obviously demand a multi-factorial analysis with each macroeconomist playing up or playing down his favorites. What must a policy maker do to make sense of this mess? This then is the sort of situation when the usual notion of cause-and-effect is not merely of interest to those who are interested in macroeconomic frameworks, but also to those who must actually formulate and implement economic policy. The imperative for the policy maker is to remain pragmatic and not get unduly caught up on whether or not macroeconomics is or will ever be a science in the deterministic sense of the term and on whether or not monetary policy is a matter of rules or discretion. So, for instance, while many readers have been taught to believe that the repeal of the Glass-Steagall Act was a causal factor in the recent crisis, Münchau reminds us that 'the Glass-Steagall Act was still mostly in place when the 1987 stock market bubble happened'. What exactly then is the significance of this regulatory provision? And, then again, Bill Clinton has argued that if the Act had been in place, 'Bank of America could not have taken over Merrill Lynch in September 2008, during the same weekend when Lehman Brothers failed'. Here then is a simple but riveting conundrum in macroeconomics which policy makers have to navigate without the certitudes of physical science to provide a foundation for their decision making. The problem then is that none of these factors per se is synonymous with the crisis, but working out the actual combination of factors in terms of their proportional share (given a particular combination of macroeconomic variables) is not easy to do either; it can at best be done on a case-by-case basis and even then it is subject to problems of interpretation. So what we have here is not merely a crisis in the banking system but also a crisis in policy making to regulate the banking sector. Some of these problems are analogous to the preoccupation with the causal factors behind the Great Depression in monetary theory. Was it merely the shrinking of the money supply that directly caused the depression? Or should money supply be interpreted only as a lag variable?

Münchau ends the book with a series of policy proposals. They include the following: the creation of 'a global credit register to improve transparency'. This means that the world's leading financial centers must set up the 
modalities to exchange data that is necessary for cross-border regulation and 'macro-prudential supervision'. It is also important to prevent firms from getting into a 'too big to fail' situation by ensuring that they do not 'accumulate assets beyond a certain threshold of the host country's GDP'. The exact ratio of the firm's assets to GDP is not given, but can be worked out by financial experts. Given the cross border character of capital flows, it is important to set up a new set of both regulatory and governance modalities through the offices of 'a global regulator'. This must include 'intraregional regulation' to reduce instances of 'cross-border regulatory arbitrage'. Münchau is aware of the skepticism expressed on matters pertaining to global governance by political economists like Dani Rodrik of Harvard, but argues that we must at least give the problem a serious go. He also argues that 'mark-to-market' rules as opposed to 'mark-to-model' rules must be thought through carefully since the former is 'procyclical', which means that the number of bankruptcies will increase under this accounting regime. It is also important to invoke 'the principle of economic intent' in matters pertaining to macro-prudential supervision to ensure greater flexibility in interpretation rather than try to anticipate all the things that can go wrong. Further suggestions for the improvement of the system include making the theoretical assumptions in the quantitative models used by rating agencies subject to empirical scrutiny by regulators, revising the rules for issuing credit default swaps by increasing the levels of 'collateral to survive a stressful situation', and considering a ban on 'naked short-selling' as some economies have already tried to do.

Münchau also goes against the conventional wisdom on capital adequacy ratios established by the Basle conventions (where the assumption is that things are getting progressively better), when he argues that 'Basle is only about solvency risk'. What is often overlooked is that 'there are no international rules to set minimum standards for liquidity'. And, finally, it is important to restructure the incentives that motivate risktaking in firms. Since Münchau's exposition and critique is based on according priority to macroeconomic factors rather than the financial sector as such, he concludes by discussing the consequences for macroeconomic policy'. There are three important consequences here which include increasing the levels of 'cooperation' between central banks and treasuries, increasing the control of central banks over their national economies, and the importance of going beyond inflation targeting by 'adopting a broader definition of stability than pure price stability'. The underlying problem here, needless to say, is that even when monetary borders are secure as in closed economies; it is difficult to demonstrate a strong cause-and-effect model despite the routine invocation of hydrodynamic metaphors in monetary theory. If however central banks go their own way - given the level of cross border transactions and capital flows - it becomes increasingly difficult to translate monetary theory into monetary policy. Therein resides the challenge for policy makers in both monetary policy and the international economy if they want to prevent the recurrence of the crises that have assailed the world since the economic meltdown of 2008. Münchau envisages a world then which 'in currency terms' is 'bipolar' and which 'in industrial terms' is 'multipolar', and where the role of Asia will continually increase as the 'center of gravity' in the years to come. 